\title{
Simulation of Urban Flood in Jinan City Based on Caflood
} Shiyuan FENG ${ }^{1, \text { a }}$, Qingguo LI $^{2, b}$

${ }^{1,2}$ College of Resource and Environment, Jinan University, Shandong 250022, China affengshiyuan@126.com, ${ }^{\text {b} 117942397 @ q q . c o m ~}$

Keywords: Urban flood simulation; Jinan City; Cell Automata; Caflood program Abstract. This study adopts urban flood control systems into a cellular automata flood model (Caflood) for simulating the temporal and spatial evolution of urban flood. Caflood, which is different from the traditional hydrological model, using the cellular automata (CA) technique to simulate storm flood. The paper established the Jinan city flood flooding simulation model which based on the Caflood, and verified the model through the first practical application in Ji'nan City, the results show that the model is reliable with high precision and short computation time. It can not only better describe the flood motion characteristic, but also be more suitable for the city flood warning and emergency response planning.

\section{Introduction}

With the development of numerical calculation and GIS, the urban storm water simulation theory and technology has made great improvement ${ }^{[1,2]}$. CADDIES Framework, which was developed by Michele Guidolin, Albert S. Chen, Nicola Pasquale in University of EXETER, is an open source rain flood simulation system. In 2015 its 1.10 version has been released. Now it has some practical application in the United Kingdom ${ }^{[3]}$ and achieved satisfying results. Caflood, a two-dimensional rainfall flood simulation model, is the core part of CADDIES Framework. In order to establish a comprehensive consideration of the streets and the topography of the city flood propagation in Ji'nan city flood model, the paper uses Caflood to simulate the flood rainstorm and calculate the urban storm flood under the design rainstorm.

\section{Caflood and WCA2D storm flood simulation model}

Caflood. Caflood program can do 2-dimensional rain flood submerged simulation calculations, its principle is the use of cellular automata $(\mathrm{CA})^{[4]}$ technology to replace the traditional shallow wave equation solution. The CA model usually consists of five essential features: discrete space, adjacent cell distribution, cell state, discrete computing time and conversion rules. The transformation rule consists of some simple operations that can control the evolution of each cell state. Therefore, CA algorithm is especially suitable for parallel computing ${ }^{[5]}$.

WCA2D model. CA put forward the WCA2D rainfall flood simulation model based on CA. The model mainly uses the normalized weight method to improve the CA2D ${ }^{[6]}$. The new method is more accurate and reasonable.

The weights represent part of the amount of water exchanged between total units. For example, the minimum value can represent the weight of the central unit. This step can be expressed by the following formula:

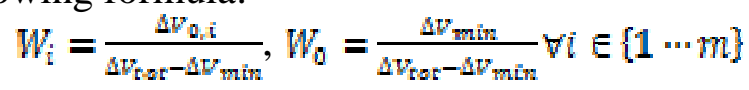

In the formula, $\mathrm{W}_{\mathrm{i}}$ is the weight of the unit $\mathrm{i}$.

The following formula is used to calculate the water depth during the update period ${ }^{[7]}$ :

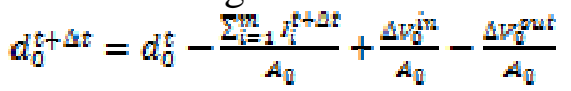

In the formula, $\mathrm{m}$ is the number of adjacent elements, $\mathrm{A}_{0}\left(\mathrm{~m}^{2}\right)$ as the center of the unit area of the lateral, $\Delta V_{0}^{i n}$ as the center unit inflow (such as reflux precipitation, upstream catchment area of inflow or from the downstream boundary). The $\Delta V_{0}^{\text {out }}$ is the center of the final output unit (such as 
water infiltration or lateral flow), $d_{0}^{t}(m) \mathrm{d}_{0}^{t}(\mathrm{~m})$ as the center unit time $\mathrm{t}$ depth, $d_{0}^{t+\Delta t}$ ( $\mathrm{m}$ ) for the next time the update center unit depth.

\section{Rainstorm flood simulation in Ji'nan City}

Research areas and main data. Ji'nan city is located in the middle of Shandong province. The geographical position is between $116^{\circ} 11^{\prime} \sim 117^{\circ} 44^{\prime} \mathrm{E}, 36^{\circ} 02^{\prime} \sim 37^{\circ} 31^{\prime} \mathrm{N}$, and the total area of the city is $8177 \mathrm{~km}^{2}$. The study area relates to the main urban areawhose area is $3257 \mathrm{~km}^{2}$.

Caflood model needs much data, and the integrity and detail of data will affect the accuracy of model simulation results. The main data required by the model include DEM data, land use data, and hydrological data.

Modeling and analysis of simulation results. The parameters of WCA2D model is rare, mainly including Roughness Global、Average Slope and so on, it is important to ensure the accuracy and reliability of the data for obtaining satisfying simulation results, including DEM, rainfall data, boundary inflow data and so on.

The initial conditions of the model, the land surface water level and the flow velocity are set to $0 \mathrm{~m} / \mathrm{s}$ in simulated area. The data of the Taiping Rive, the Xiaoqing River and the South Taiping River are all measured. No measured data of the river flow is $0 \mathrm{~m} / \mathrm{s}$ and the initial water depth is $0.1 \mathrm{~m}$. The boundary conditions and the upstream boundary of the river are computed using the rainfall runoff model, and the hydrograph results are computed. Two dimensional model land surface no longer set boundary conditions.

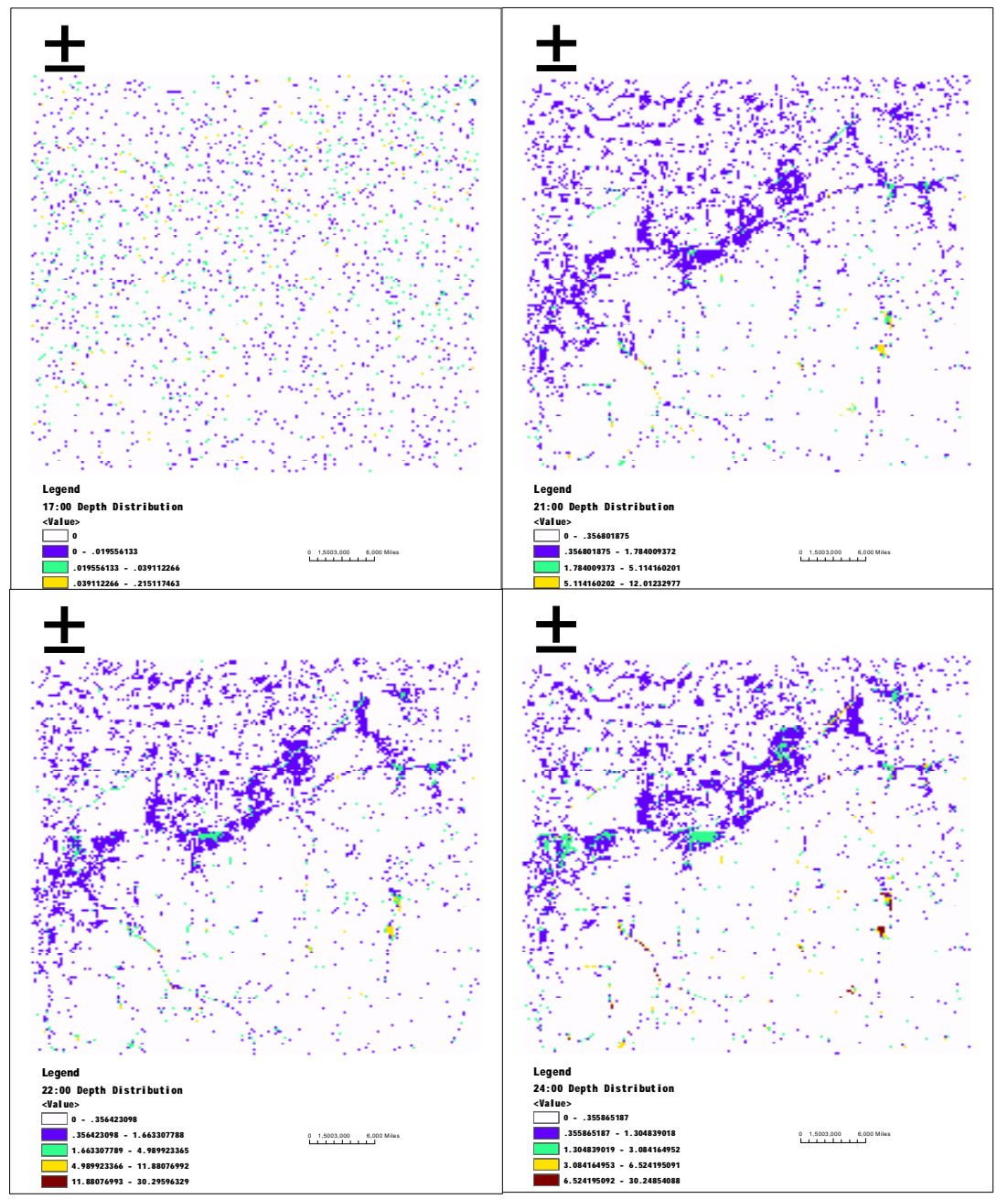

Fig. 10718 simulation results and water depth distribution in urban area 
According to the data of the study area, buiding a flood simulation model This paper uses "2007.7.18" typical rainstorm process in Ji'nan as the input of the model (Table 1), Ji'nan city flood process of the storm is simulated, and the simulation results were measured according to test data.

Tab.1 070718 rainfall schedule of typical rainstorm

\begin{tabular}{cccccccc}
\hline Duration $(1 \mathrm{~h})$ & $16: 00$ & $17: 00$ & $18: 00$ & $19: 00$ & $20: 00$ & $21: 00$ & $22: 00$ \\
\hline Intencity $(\mathrm{mm})$ & 4.9 & 66.0 & 55.8 & 11.3 & 4.4 & 2.2 & 0.6 \\
\hline
\end{tabular}

The Caflood model is a dynamic continuous process for flood inundation simulation. In order to show the temporal and spatial evolution laws of flood inundation, intercepting several typical moments (Figu re 1).

According to the simulation results, the inundated area gradually increases at 17:00-21:00, and the submergence depth also increases gradually. The most serious time is about 21:00, the simulation shows that the water started to recede at 22:00, flood basically cleared except some low-lying areas at 24:00. The simulation results and the actual situation is basically consistent with the focus of the water area in the north and central regions, Yingxiong mountain road, Jianshe road, Yuhan road, Second Ring Road and other roads are flood road.

To determine the accuracy of the model, we selected important points of investigation depth flooded of main road in Jinan as reference data, and comparing ${ }^{[8]}$ with depth which using software MIKE21 by Guibing Hou of Shandong University in 2010. (Tab. 2).

Tab. 2 calculation results of inundated water depth in urban area

\begin{tabular}{|c|c|c|c|c|c|c|}
\hline Serial number & Name & Survey depth $(\mathrm{m})$ & $\begin{array}{c}\text { Caflood } \\
\text { Calculation result } \\
\end{array}$ & deviation & $\begin{array}{c}\text { MIKE21 } \\
\text { Calculation result } \\
\end{array}$ & deviation \\
\hline 1 & Duandian Railroad Bridge & 2.45 & 2.51 & -0.06 & 1.92 & 0.53 \\
\hline 2 & Junction of Jiefang and Shanda Road & 0.5 & 0.35 & 0.15 & 0.32 & 0.18 \\
\hline 3 & Junction of Heping and Yangtouyu west Ditch & 0.5 & 0.78 & -0.27 & 0.75 & -0.25 \\
\hline 4 & Middle of Lishan Road & 0.9 & 0.92 & -0.02 & 1.41 & -0.51 \\
\hline 5 & Subdistrict office of Baotu Spring & 0.5 & 0.85 & -0.35 & 0.73 & -0.23 \\
\hline 6 & Jingshi and Shanshi Road & 0.5 & 0.29 & 0.21 & 0.59 & -0.09 \\
\hline 7 & Junction of Jingshi and Shungeng Road & 0.4 & 0.58 & -0.18 & 0.57 & -0.17 \\
\hline 8 & Junction of Liuchangshan and Jianshe Road & 1 & 1.12 & -0.12 & 1.39 & -0.39 \\
\hline 9 & Shaonian Road & 0.4 & 0.82 & -0.42 & 0.66 & -0.26 \\
\hline 10 & Wuyingshan North road Railway Bridge & 0.4 & 0.55 & -0.15 & 0.58 & -0.18 \\
\hline 11 & Yihe Railway Bridge & 2 & 1.56 & 0.44 & 1.63 & 0.37 \\
\hline 12 & Dianliu Village Intersection & 0.5 & 0.32 & 0.18 & 0.82 & -0.32 \\
\hline 13 & Sports Center under Overpass & 0.7 & 0.44 & 0.26 & 0.81 & -0.11 \\
\hline 14 & Under the Bayi Overpass & 1.1 & 1.34 & -0.24 & 1.32 & -0.22 \\
\hline 15 & Jiefang Bridge & 1 & 0.35 & 0.65 & 1.24 & -0.24 \\
\hline 16 & Shunhe Street Inn & 0.5 & 0.62 & -0.12 & 0.7 & -0.2 \\
\hline 17 & Bayi Overpass south & 0.8 & 0.51 & 0.29 & 0.99 & -0.19 \\
\hline 18 & The fourth hospital of Ji'nan & 0.2 & 0.08 & 0.12 & 0.61 & -0.41 \\
\hline 19 & Weishier Railway Bridge pump Station & 4 & 3.98 & 0.02 & 4.67 & -0.67 \\
\hline 20 & Junction of Wenhua west road and Qianfo hill & 0.5 & 0.44 & 0.06 & 0.53 & -0.03 \\
\hline 21 & Jingsan Road & 0.3 & 0.35 & -0.05 & 0.55 & -0.25 \\
\hline \multirow[t]{2}{*}{22} & Junction of xingji river and South Outer Ring & 0.7 & 0.44 & 0.26 & 0.94 & -0.24 \\
\hline & Average & & & 0.21 & & 0.27 \\
\hline
\end{tabular}

It can be seen from the table that the average error of Caflood calculation result is smaller than that of MIKE21 calculation, the calculation error of water depth calculated by Caflood software is less than 0.30 which account for $82 \%$ and the average calculation error is $0.21 \mathrm{~m}$ in the 22 measuring points. The depth error calculated by MIKE21 software is less than 0.30 which accounting for $68 \%$, and the average error is $0.27 \mathrm{~m}$. It shows that the calculated results of Caflood model agree well with the measured values and can meet the requirement of prediction accuracy. Individually, the 
calculation error of Jiefang Bridge, Shaonian Road, Yihe Railway Bridge is large, the reason may be that the existence of small area is very low-lying areas. After floods in 7th, July, Jinan carried out the transformation of municipal engineering in large scale, it changed the original terrain. And river high resolution terrain which two-dimensional model needs is characterized in detail, these affected the accuracy of the computational results. But in general, the model simulation results are good, which shows the validity of the model.

\section{Conclusion}

(1)According to the actual situation of Ji'nan City, a model of urban stormwater flood based on Caflood is constructed, and the model is verified by using "2007.07.18" flood. The results show that the model can well simulate the rainfall and waterlogging in Ji'nan City, and verify the validity of the model.

(2)Selecting 22 important roads easily flooded, comparing the measured water depth with the calculation result made by MIKE21 model. The results show that the model simulation results is good, the precision is high. And the cell automaton technology replace the traditional model of shallow water wave equation to solve it, the computational efficiency of efficiency has improved a lot compared with the traditional hydrodynamic methods.

\section{Acknowledgements}

This work was financially supported by the Shandong Provincial Water Conservancy Scientific Research and Technology Extension Project" Urban Water Regime Warning and Storm Flood Forecasting Technology"(JNCQSW201602).

The correspondence author of this article is Qingguo LI.

\section{References}

[1]Binbin SHI,donghui WAN,et al.Hydrological Frequency Analysis and Calculation Based on Compound Probability Function[J].Water Resources and Power,2014,(06):57-60.

[2]Ningning LIU,xiaofang BING,et al.Jinan Urban Rainstrom Model Based on Lattice Boltzmann Method[J].Water Resources and Power,2016,(06):48-52.

[3]Guidolin M, Chen A S, Ghimire B, et al. A weighted cellular automata 2D inundation model for rapid flood analysis[J]. Environmental Modelling \& Software, 2016, 84:378-394.

[4]Austin R J, Chen A S, Savić D A, et al. Quick and accurate Cellular Automata sewer simulator[J]. Journal of Hydroinformatics, 2014, 16(6):1359-1374.

[5]Gibson M J, Savic D A, Djordjevic S, et al. Accuracy and Computational Efficiency of 2D Urban Surface Flood Modelling Based on Cellular Automata [J]. Procedia Engineering, 2016, 154:801-810.

[6]Ghimire B, Chen A S, Guidolin M, et al. Formulation of fast 2D urban pluvial flood model using cellular automata approach[J]. Journal of Hydroinformatics, 2013, 15(3):676-686.

[7]Ghimire B, Chen A S, Djordjević S, et al. Application of cellular automata approach for fast flood simulation[C]// Computing and Control for the Water Industry 2011: Urban Water Management Challenges and Opportunities. 2011.

[8]Guibing HOU.Study of Urban Flood Numerical Simulation in Jinan City[D].ShanDong University,2012. 